\title{
HLA molecules and nasal carriage of Staphylococcus aureus isolated from dialysis and kidney transplant patients at a hospital in Southern Brazil
}

Luciana Borges Giarola ${ }^{1}$, Rosiane Ribeiro dos Santos ${ }^{2}$, João Bedendo ${ }^{3}$, Waldir Veríssimo da Silva Júnior ${ }^{4}$ and Sueli Donizete Borelli, ${ }^{5 *}$

\begin{abstract}
Background: Healthy individuals can host Staphylococcus aureus in the nasopharynx, body surface and vagina. Most invasive infections by this bacterium are endogenous, caused by strains spread from the nasopharynx of carriers. $S$. aureus is a pathogen involved in the etiology of hospital- and community-acquired infections. Transplant and dialysis patients are at risk of colonization or infection by multi-resistant S. aureus. Infection is directly linked to individual immunity, and the major histocompatibility complex (MHC) plays a crucial role in determining susceptibility to diseases. Different MHC specificities have been shown to be more frequent in individuals suffering from certain diseases. This study aimed to investigate the association between HLA class I (HLA-A and -B) and class II (HLA-DRB1) molecules and nasal carriage of $S$. aureus in dialysis and kidney transplant patients at a hospital in Southern Brazil.
\end{abstract}

Results: The sample consisted of 70 dialysis and 46 kidney transplant patients, totaling 116 patients. All subjects were typed for HLA molecules using LABType ${ }^{\circledR}$ SSO (One Lambda). Nasal swab samples of S. aureus were isolated from the nasal cavity (both nostrils) of patients undergoing dialysis or kidney transplantation.

In renal dialysis patients, HLA-A*02 was the most frequent allele in both carriers (25.5\%) and non-carriers (21.2\%) of S. aureus. Allele $A^{*} 68$ was not observed in the carrier group, but the allele was observed six times in the noncarrier group ( $p=0.0097$ ). Regarding HLA-B and HLA-DRB1, no allele was shown to be involved in protection against or susceptibility to carriage of $S$. aureus. In kidney transplant patients, allele $A^{*} 03$ was more frequent in the non-carrier (20.83\%) than in the carrier (5.88\%) group ( $p=0.0486)$. HLA-B*15 was present in carriers (5.88\%) and non-carriers $(25 \%)(p=0.0179)$. Regarding class $\|$ alleles, $\mathrm{DRB}{ }^{*} 03$ appeared to be related to susceptibility to carriage of $S$. aureus $(p=0.0319)$.

Conclusions: Our findings suggest that HLA-DRB1*03 may be involved in susceptibility to nasal carriage of $S$. aureus in transplant patients. In addition, HLA-A*68 (dialysis patients) and HLA-A*03 and HLA-B*15 (transplant patients) appear to be associated with increased resistance to $S$. aureus nasal carriage.

\section{Background}

Staphylococcus aureus is considered an important etiologic agent due to its high frequency and pathogenicity, causing diseases in both healthy and immunocompromised individuals. This microorganism is able to spread

\footnotetext{
* Correspondence: sdborelli@uem.br

${ }^{5}$ Department of Basic Health Sciences, UEM, Maringá, Brazil

Full list of author information is available at the end of the article
}

easily in the hospital environment and to develop resistance to antimicrobial agents $[1,2]$.

Approximately $20 \%$ of adults are carriers of S. aureus in the nasopharynx, another $30 \%$ carry it intermittently, and $50 \%$ are not carriers $[3,4]$. Persistent nasal carriers of $S$. aureus are at higher risk of developing infection $[5,6]$. Dialysis and kidney transplant patients are particularly prone to infection due to constant exposure to risk factors and immunosuppression $[2,7]$.
C Biomed Central

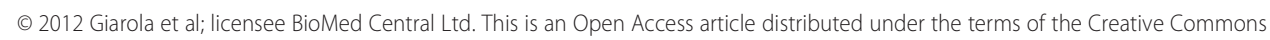
Attribution License (http://creativecommons.org/licenses/by/2.0), which permits unrestricted use, distribution, and reproduction in any medium, provided the original work is properly cited. 
Infection is directly related to individual immunity and the major histocompatibility complex (MHC)-a set of genes found on the short arm of human chromosome 6-plays a crucial role in determining susceptibility to diseases. Specifically, MHC contains a group of genes that code for several proteins expressed on the surface of a variety of cell types. In humans, these molecules are known as human leukocyte antigens (HLA) [8].

Molecules of the HLA system are classified as class I (HLA-A, -B and -C), class II (HLA-DR, -DQ and -DP), and class III. These molecules are highly polymorphic glycoproteins that differentiate themselves from one another by their location in tissues and their function. Class I molecules are present on the surface of all nucleated cells and are responsible for presenting peptides to cytotoxic $\mathrm{T}$ cells $\left(\mathrm{CD}^{+}\right)$. Class II molecules are distributed less widely, being found primarily on the surface of cells linked directly to the immune response (such as macrophages, monocytes, dendritic cells, Langerhans cells, B lymphocytes, and activated T lymphocytes), with the purpose of presenting peptides to regulatory $\mathrm{T}$ cells $\left(\mathrm{CD} 4^{+}\right)$. The class III region does not encode histocompatibility molecules, but rather other molecules such as tumor necrosis factors, C4 and C2 proteins, complement factor $\mathrm{B}$, heat shock protein, and 21-hydroxylase enzyme [9-12].

Different HLA specificities have been shown to be more frequent in individuals suffering from certain diseases, and characterizing these molecules may have important clinical implications [13-15].

The role of the HLA system in pathogenesis has been studied in several diseases, such as skin diseases [16-18], tuberculosis [19,20], psychiatric illnesses [21,22], as well as hearing [23,24], sight [25,26] and kidney [27] problems. Nasal carriage of Staphylococcus spp. has been investigated in dialysis and kidney transplant patients $[28,29]$; however, only a few studies have investigated the involvement of genetic factors in this carriage. A literature review returned only one study, published in 1983, investigating the association between HLA molecules and nasal carriage of $S$. aureus in healthy laboratory workers and outpatients [30].

Thus, this study aimed to investigate the association between HLA class I (HLA-A and -B) and class II (HLA-DRB1) molecules and nasal carriage of S. aureus in dialysis and kidney transplant patients at a hospital in Southern Brazil.

\section{Methods}

The study population consisted of 70 renal patients undergoing dialysis and 46 kidney transplant patients, totaling 116 patients. All subjects were typed for HLA class I (A, B) and class II (DRB1) molecules and evaluated for nasal carriage. Biological material, nasal discharge and blood were collected between June and November 2009.

\section{Staphylococcus aureus identification}

Nasal swab samples of $S$. aureus were isolated from the nasal cavity of patients undergoing dialysis or kidney transplantation by inserting sterile swabs into both nostrils. The material was placed in Petri dishes $(90 \times 15$ $\mathrm{mm}$ ) containing mannitol salt agar (MSA) (Becton Dickinson \& Co., BD Diagnostic Systems, USA), transferred to a test tube containing trypticase soy broth (TSB) with $6.5 \% \mathrm{NaCl}$, and then placed in a stove for 24 hours. After 24-48 hours of incubation at $37^{\circ} \mathrm{C}$, suspected $S$. aureus colonies were subjected to Gram staining and immersion microscopy. Those identified as Gram-positive cocci arranged in grape-like clusters were transferred to a TSB medium with $6.5 \% \mathrm{NaCl}$. The tube coagulase test was performed after six hours of incubation. After the identification tests, samples were stored in a TSB medium with glycerol $(20 \%)$ and frozen at $-20^{\circ} \mathrm{C}$ for later analysis.

\section{HLA typing}

Human DNA extraction: Peripheral blood was collected by venipuncture in vacuum tubes containing EDTA anticoagulant, and genomic DNA was extracted using EZ-DNA reagent, according to the manufacturer's instructions (Biological Industries, Kibbutz Beit, Haemek, Israel).

Genetic polymorphism of HLA molecules: One Lambda LABType ${ }^{(\mathbb{R}}$ SSO kit was used in combination with the Luminex ${ }^{\mathrm{TM}}$ technology for typing of HLA class I (HLA-A and -B) and class II (HLA-DRB1) alleles.

\section{Statistical analysis}

For data analysis, dialysis and transplant patients were subdivided into carriers and non-carriers of S. aureus. The number of times a given allele was found (n) and allele frequency (Af) were quantified in both patient groups. $P$-value was calculated using Fisher's exact test $(P$-value). Bonferroni correction (Pc-value) was used to calculate $\mathrm{p}$ values below 0.05 . The odds ratio (OR) and confidence interval $(95 \% \mathrm{CI})$ were calculated whenever the $\mathrm{p}$ value was lower than 0.05 .

\section{Ethical aspects}

The study was approved by the Research Ethics Committee of Universidade Estadual de Maringá (protocol no. $212 / 2009$ ), and written informed consent was obtained from all participants. The study was conducted in accordance with the provisions of the Declaration of Helsinki.

\section{Results}

Of 70 dialysis patients, 30 (42.8\%) were female and 40 (57.1\%) male. Age ranged from 22 to 85 years. Thirty- 
seven patients $(52.8 \%)$ were nasal carriers of $S$. aureus and $33(47.1 \%)$ were non-carriers.

Of 46 patients evaluated in the transplant group, 16 (34.7\%) were female and 30 (65.2\%) male. Age ranged from 18 to 64 years. Thirty-four patients $(74 \%)$ were nasal carriers of S. aureus and 12 (26\%) were non-carriers.

\section{Study association with dialysis patients and their status} as nasal carriers or non-carriers of Staphylococcus aureus Analysis of the frequency of class I, A and B alleles, and class II, DRB1 alleles, (Table 1) showed that HLA-A*02 was the most frequent allele in both carriers (25.5\%) and non-carriers $(21.2 \%)$. HLA-A*68 was not observed in the carrier group, but the allele was observed six times in the non-carrier group ( $p=0.0097)$. This result suggests a tendency towards protection or resistance against nasal carriage of $S$. aureus. Regarding HLA-B and -DRB1, no allele was shown to be involved in protection against or susceptibility to carriage of $S$. aureus.

\section{Study association with kidney transplant patients and} their status as nasal carriers or non-carriers of Staphylococcus aureus

As shown in Table 2, HLA-A*03 was more frequent in the non-carrier group $(20.83 \%)$ than in the carrier group $(5.88 \%)(p=0.0486)$, which suggests a tendency towards

Table 1 Allele frequency (HLA-A, HLA-B, and HLA-DRB1) in the group of renal patients undergoing dialysis, nasal carriers and non-carriers of Staphylococcus aureus

\begin{tabular}{|c|c|c|c|c|c|c|c|c|c|c|c|c|c|c|c|c|c|}
\hline \multirow[b]{2}{*}{ Allele } & \multicolumn{2}{|c|}{ Carriers } & \multicolumn{2}{|c|}{ Non-carriers } & \multirow[b]{2}{*}{$P$-value } & \multirow[b]{2}{*}{ Pc-value } & \multirow[b]{2}{*}{ OR } & \multirow[b]{2}{*}{$95 \% \mathrm{Cl}$} & \multirow[b]{2}{*}{ Allele } & \multicolumn{2}{|c|}{ Carriers } & \multicolumn{2}{|c|}{ Non-carriers } & \multirow[b]{2}{*}{$P$-value } & \multirow[b]{2}{*}{ Pc-value } & \multirow[b]{2}{*}{ OR } & \multirow[b]{2}{*}{$95 \% \mathrm{Cl}$} \\
\hline & $n$ & Af\% & $\mathrm{n}$ & $A f \%$ & & & & & & $n$ & $A f \%$ & $\mathrm{n}$ & $A f \%$ & & & & \\
\hline HLA-A & & & & & & & & & HLA-B & & & & & & & & \\
\hline 01 & 9 & 12.1 & 6 & 9.0 & ns & - & & & 05 & 0 & - & 1 & 1.5 & ns & - & & \\
\hline 02 & 19 & 25.6 & 14 & 21.2 & ns & - & & & 07 & 4 & 5.4 & 6 & 9.0 & ns & - & & \\
\hline 03 & 6 & 8.1 & 7 & 10.6 & ns & - & & & 08 & 4 & 5.4 & 5 & 7.5 & ns & - & & \\
\hline 11 & 6 & 8.1 & 4 & 6.0 & ns & - & & & 13 & 1 & 1.3 & 0 & - & ns & - & & \\
\hline 23 & 2 & 2.7 & 2 & 3.0 & ns & - & & & 14 & 0 & - & 2 & 3.0 & ns & - & & \\
\hline 24 & 9 & 12.1 & 10 & 15.1 & ns & - & & & 15 & 1 & 1.3 & 3 & 4.5 & ns & - & & \\
\hline 25 & 3 & 4.0 & 0 & - & ns & - & & & 16 & 0 & - & 1 & 1.5 & ns & - & & \\
\hline 26 & 2 & 2.7 & 5 & 7.5 & ns & - & & & 18 & 7 & 9.4 & 6 & 9.0 & ns & - & & \\
\hline 29 & 3 & 4.0 & 1 & 1.5 & ns & - & & & 22 & 1 & 1.3 & 0 & - & ns & - & & \\
\hline 30 & 5 & 6.7 & 5 & 7.5 & ns & - & & & 27 & 2 & 2.7 & 0 & - & ns & - & & \\
\hline 31 & 3 & 4.0 & 1 & 1.5 & ns & - & & & 35 & 6 & 8.1 & 4 & 6.0 & ns & - & & \\
\hline 32 & 2 & 2.7 & 2 & 3.0 & ns & - & & & 38 & 3 & 4.0 & 3 & 4.5 & ns & - & & \\
\hline 33 & 2 & 2.7 & 2 & 3.0 & ns & - & & & 39 & 3 & 4.0 & 4 & 6.0 & ns & - & & \\
\hline 34 & 2 & 2.7 & 1 & 1.5 & ns & - & & & 40 & 1 & 1.3 & 2 & 3.0 & ns & - & & \\
\hline 68 & 0 & - & 6 & 9.0 & 0.0097 & 0.1552 & - & - & 41 & 0 & - & 1 & 1.5 & ns & - & & \\
\hline 74 & 1 & 1.3 & 0 & - & ns & - & & & 42 & 2 & 2.7 & 1 & 1.5 & ns & - & & \\
\hline HLA-DRB1 & & & & & & & & & 44 & 6 & 8.1 & 5 & 7.5 & ns & - & & \\
\hline 01 & 3 & 4.0 & 5 & 7.5 & ns & - & & & 45 & 2 & 2.7 & 0 & - & ns & - & & \\
\hline 03 & 1 & 1.3 & 2 & 3.0 & ns & - & & & 49 & 2 & 2.7 & 2 & 3.0 & ns & - & & \\
\hline 04 & 10 & 13.5 & 13 & 19.7 & ns & - & & & 50 & 1 & 1.3 & 3 & 4.5 & ns & - & & \\
\hline 07 & 8 & 10.8 & 6 & 9.0 & ns & - & & & 51 & 7 & 9.4 & 8 & 12.1 & ns & - & & \\
\hline 08 & 5 & 6.7 & 2 & 3.0 & ns & - & & & 52 & 2 & 2.7 & 2 & 3.0 & ns & - & & \\
\hline 09 & 1 & 1.3 & 0 & - & ns & - & & & 53 & 1 & 1.3 & 2 & 3.0 & ns & - & & \\
\hline 10 & 3 & 4.0 & 3 & 4.5 & ns & - & & & 55 & 4 & 5.4 & 0 & - & ns & - & & \\
\hline 11 & 17 & 22.9 & 11 & 16.6 & ns & - & & & 57 & 3 & 4.0 & 0 & - & ns & - & & \\
\hline 13 & 6 & 8.1 & 7 & 10.6 & ns & - & & & 58 & 1 & 1.3 & 2 & 3.0 & ns & - & & \\
\hline 14 & 5 & 6.7 & 1 & 1.5 & ns & - & & & 60 & 2 & 2.7 & 1 & 1.5 & ns & - & & \\
\hline 15 & 3 & 4.0 & 7 & 10.6 & ns & - & & & 61 & 2 & 2.7 & 0 & - & ns & - & & \\
\hline 16 & 5 & 6.7 & 6 & 9.0 & ns & - & & & 62 & 4 & 5.4 & 0 & - & ns & - & & \\
\hline 17 & 3 & 4.0 & 3 & 4.5 & ns & - & & & 65 & 1 & 1.3 & 2 & 3.0 & ns & - & & \\
\hline 18 & 1 & 1.3 & 0 & - & ns & - & & & 81 & 1 & 1.3 & 0 & - & ns & - & & \\
\hline 51 & 1 & 1.3 & 0 & - & ns & - & & & & & & & & & & & \\
\hline 52 & 2 & 2.7 & 0 & - & ns & - & & & & & & & & & & & \\
\hline
\end{tabular}

$N$ number of times the allele was found; $A f$ allele frequency; $P$-value = calculated by Fisher's exact test; Pc-value = Bonferroni-corrected P-value; OR odds ratio; $95 \% \mathrm{Cl} 95 \%$ confidence interval; $n s$ non-significant $(p>0.05)$ 
Table 2 Allele frequency (HLA-A, HLA-B, and HLA-DRB1) in the group kidney transplant patients, nasal carriers and non-carriers of Staphylococcus aureus

\begin{tabular}{|c|c|c|c|c|c|c|c|c|c|c|c|c|c|c|c|c|c|}
\hline \multirow[b]{2}{*}{ Allele } & \multicolumn{2}{|c|}{ Carriers } & \multicolumn{2}{|c|}{$\begin{array}{c}\text { Non- } \\
\text { carriers }\end{array}$} & \multirow[b]{2}{*}{$P$-value } & \multirow[b]{2}{*}{ Pc-value } & \multirow[b]{2}{*}{ OR } & \multirow[b]{2}{*}{$95 \% \mathrm{Cl}$} & \multirow[b]{2}{*}{ Allele } & \multicolumn{2}{|c|}{ Carriers } & \multicolumn{2}{|c|}{$\begin{array}{c}\text { Non- } \\
\text { carriers }\end{array}$} & \multirow[b]{2}{*}{$P$-value } & \multirow[b]{2}{*}{ Pc-value } & \multirow[b]{2}{*}{ OR } & \multirow[b]{2}{*}{$95 \% \mathrm{Cl}$} \\
\hline & $n$ & Af\% & $\mathrm{n}$ & $A f \%$ & & & & & & $\bar{n}$ & Af\% & $n$ & Af\% & & & & \\
\hline HLA-A & & & & & & & & & HLA-B & & & & & & & & \\
\hline 01 & 9 & 13.24 & 2 & 8.33 & ns & - & & & 07 & 5 & 7.35 & 1 & 4.17 & ns & & & \\
\hline 02 & 21 & 30.88 & 6 & 25.0 & ns & - & & & 08 & 6 & 8.82 & 0 & - & ns & & & \\
\hline 03 & 4 & 5.88 & 5 & 20.83 & 0.0486 & 0.7776 & 0.2375 & 0.0579-0.9738 & 12 & 0 & - & 1 & 4.17 & ns & & & \\
\hline 11 & 2 & 2.94 & 0 & - & ns & - & & & 13 & 2 & 2.94 & 1 & 0.417 & ns & & & \\
\hline 23 & 1 & 1.47 & 1 & 4.17 & ns & - & & & 14 & 3 & 4.41 & 0 & - & ns & & & \\
\hline 24 & 9 & 13.24 & 2 & 8.33 & ns & - & & & 15 & 4 & 5.88 & 6 & 25.0 & 0.0179 & 0.4833 & 0.1875 & $0.0477-0.7371$ \\
\hline 26 & 2 & 2.94 & 1 & 4.17 & ns & - & & & 18 & 2 & 2.94 & 1 & 4.17 & ns & & & \\
\hline 28 & 0 & - & 1 & 4.17 & ns & - & & & 27 & 0 & - & 1 & 4.17 & ns & & & \\
\hline 29 & 4 & 5.88 & 0 & - & ns & - & & & 35 & 8 & 11.76 & 2 & 8.33 & ns & & & \\
\hline 30 & 6 & 8.82 & 1 & 4.17 & ns & - & & & 37 & 2 & 2.94 & 1 & 4.17 & ns & & & \\
\hline 31 & 2 & 2.94 & 1 & 4.17 & ns & - & & & 38 & 1 & 1.47 & 0 & - & ns & & & \\
\hline 32 & 1 & 1.47 & 1 & 4.17 & ns & - & & & 39 & 2 & 2.94 & 0 & - & ns & & & \\
\hline 33 & 3 & 4.41 & 0 & - & ns & & & & 40 & 1 & 1.47 & 3 & 12.50 & ns & & & \\
\hline 36 & 1 & 1.47 & 0 & - & ns & - & & & 41 & 1 & 1.47 & 1 & 4.17 & ns & & & \\
\hline 66 & 1 & 1.47 & 0 & - & ns & - & & & 42 & 1 & 1.47 & 0 & - & ns & & & \\
\hline 68 & 2 & 2.94 & 3 & 12.50 & ns & - & & & 44 & 5 & 7.35 & 3 & 12.50 & ns & & & \\
\hline HLA-DRB1 & & & & & & & & & 45 & 2 & 2.94 & 0 & - & ns & & & \\
\hline 01 & 3 & 4.41 & 0 & - & ns & - & & & 47 & 0 & - & 1 & 4.17 & ns & & & \\
\hline 03 & 12 & 17.65 & 0 & - & 0.0319 & 0.4785 & & & 49 & 4 & 5.88 & 0 & - & ns & & & \\
\hline 04 & 9 & 13.24 & 3 & 12.50 & ns & - & & & 51 & 6 & 8.82 & 1 & 4.17 & ns & & & \\
\hline 07 & 3 & 4.41 & 4 & 16.67 & ns & - & & & 52 & 3 & 4.41 & 0 & - & ns & & & \\
\hline 08 & 2 & 2.94 & 2 & 8.33 & ns & - & & & 53 & 1 & 1.47 & 0 & - & ns & & & \\
\hline 09 & 3 & 4.41 & 1 & 4.17 & ns & - & & & 55 & 1 & 1.47 & 0 & - & ns & & & \\
\hline 10 & 0 & - & 1 & 4.17 & ns & - & & & 57 & 4 & 5.88 & 0 & - & ns & & & \\
\hline 11 & 13 & 19.12 & 6 & 25.0 & ns & - & & & 58 & 2 & 2.94 & 1 & 4.17 & ns & & & \\
\hline 12 & 0 & - & 2 & 8.33 & ns & - & & & 62 & 1 & 1.47 & 0 & - & ns & & & \\
\hline 13 & 6 & 8.82 & 1 & 4.17 & ns & - & & & 70 & 1 & 1.47 & 0 & - & ns & & & \\
\hline 14 & 5 & 7.35 & 0 & - & ns & - & & & & & & & & & & & \\
\hline 15 & 7 & 10.29 & 2 & 8.33 & ns & - & & & & & & & & & & & \\
\hline 16 & 2 & 2.94 & 2 & 8.33 & ns & - & & & & & & & & & & & \\
\hline 17 & 2 & 2.94 & 0 & - & ns & - & & & & & & & & & & & \\
\hline 18 & 1 & 1.47 & 0 & - & ns & - & & & & & & & & & & & \\
\hline
\end{tabular}

$N$ number of times the allele was found; $A f$ allele frequency; $P$-value = calculated by Fisher's exact test; Pc-value = Bonferroni-corrected $P$-value; $O R$ odds ratio; $95 \% \mathrm{Cl} 95 \%$ confidence interval; $n$ s non-significant $(p>0.05)$

protection against carriage of $S$. aureus. HLA-B*15 also showed a trend towards protection against carriage (carriers: $5.88 \%$; non-carriers: $25 \%)(p=0.0179)$. Regarding class II alleles, DRB1*03 appeared to be related to susceptibility to carriage of $S$. aureus $(p=0.0319)$.

\section{Discussion}

The molecules of the HLA system, which are directly linked to the immune response, play a crucial role in the susceptibility to or protection against infectious diseases [31]. The determination of these molecules is often used in association studies with various illnesses, allowing a search for specific markers of susceptibility or resistance
$[32,33]$. In our study, we demonstrated that certain HLA alleles could be involved in nasal carriage of $S$. aureus in dialysis and kidney transplant patients.

During the literature review, we found only one study on HLA and nasal carriage of S. aureus [30], which employed the serological method of HLA typing. That study analyzed healthy laboratory workers and patients attending an outpatient clinic in Dublin and Galway, Ireland. A positive association was found between HLA-DR3 antigen and carriage of S. aureus, making individuals more susceptible to carrying the bacterium. Class I (HLA-Bw35) and class II (HLA-DR2 and HLA-DR1) antigens were also shown to be 
involved in resistance against non-carriage of the bacterium.

The present study contributed to confirm the involvement of HLA-DRB1*03 (serological equivalent DR3) as a possible genetic marker for susceptibility to nasal carriage of $S$. aureus. It also contributed to demonstrate the involvement of HLA class I specificities (-A*03, $-A^{*} 68$, and $\left.-B^{*} 15\right)$ as protective factors against nasal carriage of $S$. aureus in renal patients.

The importance of identifying patients carrying $S$. aureus, in particular those with a multi-resistant profile, lies in the fact that this pathogen is linked to endogenous infections [34]. In that sense, it is worth noting that infectious diseases exert selective genetic pressure, and the genes involved in the immune response are the most numerous and polymorphic of the human genome, thereby indicating the evolutionary advantages of the immune response to a wide variety of pathogens. This is evidenced by the participation of HLA in the presentation of foreign peptides to immune system cells [35].

\section{Conclusions}

Our findings suggest that HLA-DRB1*03 may be involved in susceptibility to nasal carriage of $S$. aureus in transplant patients. In addition, HLA-A*68 (dialysis patients) and HLA-A*03 and HLA-B*15 (transplant patients) appear to be associated with increased resistance to S. aureus nasal carriage.

Further studies are warranted to clarify the role of HLA as a genetic marker in resistance against or susceptibility to carriage of $S$. aureus. Establishing the role of host genetic factors should contribute to a better understanding of infectious conditions as well as to develop new therapies according to the progress in the field of pharmacogenetics.

\section{Availability of supporting data}

The data set supporting the results of this article is available in the repository of Universidade Estadual de Maringá (UEM), at UEM Digital Library, under no. VTLS 000184756/www.bce.uem.br.

\section{Acknowledgements}

The authors gratefully acknowledge the participation of the patients. This study received financial support from Fundação Araucária, Paraná, Brazil.

\footnotetext{
Author details

${ }^{1}$ Ingá/UNINGÁ-Maringá Nursing College, Universidade Estadual de Maringá (UEM), Maringá, Brazil. ${ }^{2}$ Health Sciences Center, UEM, Maringá, Brazil. ${ }^{3}$ Department of Nursing, UEM, Maringá, Brazil. ${ }^{4}$ Department of Statistics, UEM, Maringá, Brazil. ${ }^{5}$ Department of Basic Health Sciences, UEM, Maringá, Brazil. ${ }^{6}$ Universidade Estadual de Maringá (UEM), Av. Colombo, 5790, Zona 07, Maringá, Paraná, Brazil 87020-900.
}

\section{Authors' contributions}

SDB carried out HLA typing, drafted the manuscript and revised it critically for the intellectual content. RRS participated in the collection of biological material, processing and analysis of data. JB participated in the design of the study, helped to draft the manuscript and revised it critically for the intellectual content. WVS participated in the design of the study and performed the statistical analysis. LBG participated in the collection of biological material, processing and analysis of data, helped to draft the manuscript and revised it critically for the intellectual content. All authors read and approved the final manuscript.

\section{Competing interests}

The authors declare that they have no competing interests.

Received: 10 November 2011 Accepted: 9 February 2012

Published: 9 February 2012

\section{References}

1. Enright MC, Robinson DA, Randle G, Feil EJ, Grundmann H, Spratt BG: The evolutionary history of methicillin-resistant Staphylococcus aureus (MRSA). Proc Natl Acad Sci USA 2002, 99(11):7687-7692.

2. Vandecasteele SJ, Boelaert JR, De Vriese AS: Staphylococcus aureus infections in hemodialysis: what a nephrologist should know. Clin J Am Soc Nephrol 2009, 4(8):1388-1400.

3. Boyce JM: Methicillin-resistant Staphylococcus aureus: a continuing infection control challenge. Eur J Clin Microbiol Infect Dis 1994, 13(1):45-49.

4. Wertheim HF, Melles DC, Vos MC, van Leeuwen W, van Belkum A, Verbrugh HA, Nouwen $J$ : The role of nasal carriage in Staphylococcus aureus infections. Lancet Infect Dis 2005, 5(12):751-762.

5. Gonzalez-Zorn B, Senna JP, Fiette L, Shorte S, Testard A, Chignard M, Courvalin P, Grillot-Courvalin C: Bacterial and host factors implicated in nasal carriage of methicillin-resistant Staphylococcus aureus in mice. Infect Immun 2005, 73(3):1847-1851.

6. van Leeuwen WB, Melles DC, Alaidan A, Al-Ahdal M, Boelens HA, Snijders SV, Wertheim H, van Duijkeren E, Peeters JK, van der Spek PJ, et al: Host- and tissue-specific pathogenic traits of Staphylococcus aureus. J Bacteriol 2005, 187(13):4584-4591.

7. Ghasemian R, Najafi N, Makhlough A, Khademloo M: Frequency of nasal carriage of Staphylococcus aureus and its antimicrobial resistance pattern in patients on hemodialysis. Iran J Kidney Dis 2010, 4(3):218-222.

8. Peakman M, Vergan D: Basic and clinical immunology New York: Churchill Livingstone; 1997.

9. Pamer E, Cresswell P: Mechanisms of MHC class I-restricted antigen processing. Annu Rev Immunol 1998, 16:323-358.

10. Navarrete CV: The HLA system in blood transfusion. Baillieres Best Pract Res Clin Haematol 2000, 13(4):511-532.

11. Turner D: The human leucocyte antigen (HLA) system. Vox Sang 2004, 87(Suppl 1):87-90.

12. Alves C, Vieira N, Meyer I, Alves CO, Toralles MBP, Oliveira MdFSP: Human histocompatibility antigens and Dermatology: from research to clinical practice. An bras dermatol 2006, 81(1):65-73.

13. Neustadt DH: Ankylosing spondilitis. Postgrad Med 1977, 61(1):124-135.

14. Singh R, Kaul R, Kaul A, Khan K: A comparative review of HLA associations with hepatitis $B$ and $C$ viral infections across global populations. World J Gastroenterol 2007, 13(12):1770-1787.

15. Jacobson EM, Huber A, Tomer $Y$ : The HLA gene complex in thyroid autoimmunity: from epidemiology to etiology. J Autoimmun 2008, 30(1-2):58-62

16. Arnett FC: HLA and genetic predisposition to lupus erythematosus and other dermatologic disorders. J Am Acad Dermatol 1985, 13(3):472-481.

17. Biral AC, Magalhaes RF, Wastowski IJ, Simoes R, Donadi EA, Simoes AL, Mendes-Junior CT, Tanaka AM, Kraemer MH: Association of HLA-A, -B, -C genes and TNF microsatellite polymorphism with psoriasis vulgaris: a study of genetic risk in Brazilian patients. Eur J Dermatol 2006, 16(5):523-529.

18. Belazarian L: New insights and therapies for teenage psoriasis. Curr Opin Pediatr 2008, 20(4):419-424

19. John GT, Murugesan K, Jeyaseelan L, Pulimood RB, Jacob CK, Shastry JC: HLA phenotypes in Asians developing tuberculosis on dialysis or after renal transplantation. Natl Med J India 1995, 8(3):144-146.

20. Harfouch-Hammoud El, Daher NA: Susceptibility to and severity of tuberculosis is genetically controlled by human leukocyte antigens. Saudi Med J 2008, 29(11):1625-1629. 
21. Gaughran F: Immunity and schizophrenia: autoimmunity, cytokines, and immune responses. Int Rev Neurobiol 2002, 52:275-302.

22. Nunes SO, Borelli SD, Matsuo T, Watanabe MA, Itano EN: The association of the HLA in patients with schizophrenia, schizoaffective disorder, and in their biological relatives. Schizophr Res 2005, 76(2-3):195-198.

23. Yeo SW, Chang KH, Suh BD, Kim TG, Han H: Distribution of HLA-A, -B and -DRB1 alleles in patients with sudden sensorineural hearing loss. Acta Otolaryngol 2000, 120(6):710-715.

24. Amor-Dorado JC, Paco L, Martin J, Lopez-Nevot MA, Gonzalez-Gay MA: Human leukocyte antigen-DQB1 and -DRB1 associations in patients with idiopathic sudden sensorineural hearing loss from a defined population of Northwest Spain. Acta Otolaryngol 2005, 125(12):1277-1282.

25. Quiroz-Mercado H, Suarez-Licona A, Fromow-Guerra J, Lopez-Carasa G, Cardenas-Hernandez R, Ruiz-Morales JA, Portal-Celhay C, Granados J: Human lymphocyte antigen DR7 protects against proliferative retinopathy with type II diabetes mellitus. Arch Med Res 2002, 33(2):123-127.

26. Ueta M, Tokunaga $K$, Sotozono C, Inatomi T, Yabe T, Matsushita M, Mitsuishi Y, Kinoshita S: HLA class I and II gene polymorphisms in Stevens-Johnson syndrome with ocular complications in Japanese. $\mathrm{Mol}$ Vis 2008, 14:550-555.

27. Koonin EV, Altschul SF, Bork P: BRCA1 protein products ... Functional motifs. Nat Genet 1996, 13(3):266-268.

28. Alonso-Morquecho A, Flores-Preciado H, Martínez-García MC: Prevalence of infection in patients with central venous catheters. Revista Enf IMSS 2000, 8(3):139-143.

29. Ferreira V, Andrade D, Santos CB, Neto MM: Infection in patient with temporary double-lumen catheter for hemodialysis. Rev Panam Infectol 2005, 7(2):16-21.

30. Kinsman OS, McKenna R, Noble WC: Association between histocompatability antigens (HLA) and nasal carriage of Staphylococcus aureus. J Med Microbiol 1983, 16(2):215-220.

31. Blackwell JM, Jamieson SE, Burgner D: HLA and infectious diseases. Clin Microbiol Rev 2009, 22(2):370-385, Table of Contents.

32. Caillat-Zucman S: Molecular mechanisms of HLA association with autoimmune diseases. Tissue Antigens 2009, 73(1):1-8.

33. Schlosstein $\mathrm{L}$, Terasaki PI, Bluestone R, Pearson CM: High association of an HL-A antigen, W27, with ankylosing spondylitis. N Engl J Med 1973, 288(14):704-706

34. Burian M, Wolz C, Goerke C: Regulatory adaptation of Staphylococcus aureus during nasal colonization of humans. PLoS One 2010, 5(4):e10040

35. Burgner D, Jamieson SE, Blackwell JM: Genetic susceptibility to infectious diseases: big is beautiful, but will bigger be even better? Lancet Infect Dis 2006, 6(10):653-663.

doi:10.1186/1756-0500-5-90

Cite this article as: Giarola et al: HLA molecules and nasal carriage of Staphylococcus aureus isolated from dialysis and kidney transplant patients at a hospital in Southern Brazil. BMC Research Notes 2012 5:90.

\section{Submit your next manuscript to BioMed Central and take full advantage of:}

- Convenient online submission

- Thorough peer review

- No space constraints or color figure charges

- Immediate publication on acceptance

- Inclusion in PubMed, CAS, Scopus and Google Scholar

- Research which is freely available for redistribution

Submit your manuscript at www.biomedcentral.com/submit
Biomed Central 